\title{
New data on the winged fruits of Carpolithus prangosoides Berry from the Eocene of western Tennessee and Kentucky
}

\author{
RACHEL G. REBACK* and STEVEN R. MANCHESTER \\ Florida Museum of Natural History, Dickinson Hall, Gainesville FL 32611-7800 USA; \\ e-mails: Rachel.Rebach@ufl.edu, Steven@flmnh.ufl.edu
}

Received 26 February 2020; accepted for publication 16 June 2020

\begin{abstract}
We reexamined the morphology of the winged fruits Carpolithus prangosoides Berry (later synonym: Terminalia vera Berry) from the Eocene Claiborne Formation of southeastern North America, based on original and more recently collected specimens from several localities in Tennessee and Kentucky, USA. Physical and virtual sections of the fossils allow for more detailed documentation of wing morphology. The fruits are ellipsoidal, with five main lateral wings which bear radiating reticulate venation that forms loops near the margin. None of the fruits show pedicel or style remnants, but a basal pedicel scar was observed at the end opposite to the prominent, persistent sepals, indicating that the perianth was epigynous. A comparison with all known families having fin-winged fruits was conducted to assess possible affinities of $C$. prangosoides. Although no modern genus was found to match these fossils, the available characters, including the five sepals, suggest that it belongs to the Eudicot clade, likely in the Pentapetalae. However, the prior suggestion of combretaceous affinity is rejected based on differences in wing number and venation. We reviewed other North American reports of combretaceous fossils, concluding that only a few of them are reliable records for the family.
\end{abstract}

KEYWORDS: fossil, Combretaceae, Claiborne Formation

\section{INTRODUCTION}

The Eocene flora from clay deposits of the Claiborne Formation in western Tennessee has been studied for more than a century (Berry 1916, 1930; Dilcher and Potter 1980, Moore et al., 2003, Wang et al., 2013). During recent decades, more taxa have been documented in detail, and the familial and generic affinities have been assessed in relation to modern taxa. However, the morphological details and systematic affinities of many fossils remain poorly understood. Here we revisit the winged fruits formerly referred to Carpolithus prangosoides (Berry, 1916), and subsequently Terminalia vera (Berry, 1926). Continued collection work at the Claiborne clay pits by David L.

Corresponding author
Dilcher and his students and colleagues has yielded additional specimens of $C$. prangosoides, allowing us to learn more about their morphology and variability. Here we describe the species in greater detail, including new information on their three-dimensional morphology as revealed by physical sectioning and by micro-CT scanning.

Winged fruits are useful in taxonomic investigations because they provide numerous morphological characters for the wing (e.g., number, shape, orientation, and venation), features of internal structure (e.g., placentation, and number of seeds), as well as remnants of the floral structure. Many forms of winged fruits are known among extant angiosperms, including those with asymmetrical wings of the kind 
typified by Acer (e.g., Mirle and Burnham, 1999), those with a whorl of persistent perianth lobes (e.g., Astronium, Ruprechtia), those with a flange surrounding the seed in a single plane (e.g., Ulmus), and the radially finned fruits (e.g., Balfouradendron, Combretum, Pentace) for which more than 140 extant genera in 45 families have been recognized (Manchester and O'Leary, 2010).

Wang et al. (2013) placed Berry's Terminalia vera in synonymy with his earlierdescribed species Carpolithus prangosoides, and described additional specimens from the Warman clay pit of Henry County, Tennessee. Here we re-examined the holotype and other specimens from many localities to document the morphology in greater detail and determine whether the identification attribution to Terminalia and/or other Combretaceae could be confirmed. Although there are general similarities, the details of morphology lead us to reject the prior taxonomic assignment. Here we present an emended diagnosis and discuss the similarities and differences versus various extant taxa with fin-winged fruits. We also critically review the reports of other Combretaceae in the North American fossil record.

\section{MATERIALS AND METHODS}

We examined 39 specimens of Carpolithus prangosoides Berry winged fruits from paleobotanical collections at the Smithsonian Natural History Museum, Washington, D.C. (USNM), Florida Museum of Natural History, Gainesville, Florida (UF), and Field Museum, Chicago (FMNH). They were collected from clay pits in the middle Eocene Claiborne Formation of western Tennessee and Kentucky. Large portions of the flora, including the species considered here, were monographed by Berry $(1916,1930)$. The middle Eocene age estimate of $\sim 45 \mathrm{Ma}$ is based on palynological correlations (Dilcher and Potter, 1980; Elsik and Dilcher, 1974). The commercial clay pits from which these specimens were collected included Buchanan (UF locality 15806), Como (UF loc. 18810), Dawson (UF loc.18903), Grable (UF loc. 18952), Lawrence (UF loc. 15816), Puryear (UF loc. 15820), Warman (UF loc. 15826, 19326) and Wilbank (UF loc. 18884) in western Tennessee, and Bell City (15803) and Lamkin (UF loc. 15815) in adjacent Kentucky.

The fossils were initially exposed by splitting the clay in the field, revealing the fruits in longitudinal section. Because the plane of fracture usually exposes only two of the wings, more detailed preparation was employed to determine the full number of wings. A dissecting microscope was used to examine the details of the fruits, and sediment was chipped away with needles to expose more details of the wings. To reveal the complete complement of wings, both counterpart halves of two specimens were reassembled and then fractured transversely. To control the orientation of the transverse fracture, we used a dry circular diamond saw to pre-cut the surrounding clay in the desired plane. Then, grasping each side of the specimen by hand, we applied a slight torque until the specimen snapped cleanly apart in a transverse plane. This procedure reduced the smearing of clay that would occur if the diamond blade had passed directly through the fossil.

The fossils were studied with a Zeiss M4 dissecting microscope to document details of venation. Photographs of both extant and fossil fruits were made with a Canon Rebel XSI digital SLR camera with an EFS 60 macro lens. In addition, selected specimens were $\mathrm{x}$-rayed with both counterpart halves bound together. This was done at the University of Florida College of Engineering Nanoscale Research Facility with a GE Phoenix V|tome $\mid x m 240$ CT scanner. We used a Tungsten reflection target and $0.5 \mathrm{~mm}$ copper filter, at $120 \mathrm{kV}$ and $200 \mu \mathrm{A}$, with voxel size of $33 \mu \mathrm{m}$, obtaining 2300 images from which a 3 -dimensional reconstruction was prepared. Resulting datasets from micro-CT were analyzed with Avizo 9.0 Lite (FEI Visualization Science Group, Bordeaux, France) and VG Studio Max (3.2) to provide volume renderings, isosurface renderings, and virtual sections in transverse and longitudinal orientations. Surface files exported from Avizo were further investigated with Meshlab 2016.12 (meshlab.sourceforge.net; Cignoni et al., 2008) to provide surface views of wings that are obscured from optical viewing due to the surrounding opaque clay matrix.

We surveyed extant angiosperm families for the occurrence of radially finned fruits to provide an improved context for evaluating the broader affinities of these fossils. Extant fruits were studied at the Gray (GH) and Arnold Arboretum (A) herbaria at Harvard University, Cambridge, MA; the US National Museum at the Smithsonian Institution, Washington, DC (US); the Missouri Botanical Garden (MO); the University of Florida herbarium (FLAS); the Florida Museum Paleobotanical modern reference collection (UFPC); and the United States National Seed Herbarium at the National Arboretum, Washington, DC (BARC). The extant fruits were photographed at the macro level with reflected lighting to reveal external morphology and/or with transmitted light from a light table to reveal venation patterns. During the same herbarium visits, a broader survey of fin-winged fruits in other angiosperm families was also conducted (Manchester and O'Leary, 2010) to aid in assessing the affinities of various fossil remains.

\section{RESULTS}

\section{Carpolithes prangosoides Berry}

Pl. 1, 2

Basionym. Carpolithes prangosoides Berry 1916, USGS Prof. Paper 91, p. 351, Pl. 104, fig. 9; Wang, Blanchard et Dilcher 2013, Palaeontologia Electronica, 16(3), p. 50, fig. 3. 
1916 Carpolithus henryensis Berry, USGS Prof. Paper 91, p. 352, Pl. 112, fig. 16.

1926 Terminalia vera Berry, Torrey Botanical Club Bulletin 53, p. 61, figs 1-5.

1930 Terminalia vera Berry, USGS Prof. Paper 156, p. 119, Pl. 49, figs 21-27.

Holotype. USNM 36005, Puryear, Tennessee (Pl. 1, fig. 3; Berry, 1916: Pl. 104, fig. 9).

Emended diagnosis. Fruit fin-winged with five main wings, usually radially symmetrical, appearing bisymmetric in face view, elliptical in lateral outline. Pedicel not observed. Style not persistent. Five prominent rounded sepals $\sim 2.1-3.5 \mathrm{~mm} \mathrm{~mm}$ high and $2.0 \mathrm{~mm}$ wide, arising from the fruit apex, alternating in position with the wings. Fruit length, including sepals, 1.0-2.3 (mean 1.8) $\mathrm{cm}$, width 0.5-1.5 (mean $0.9) \mathrm{cm}, 1.2$ to 2.5 times higher than wide. Central body smooth or longitudinally striate, fusiform/elliptical, tapered basally and rounded to truncate apically, with five fin-like, radiating lateral wings. Each wing lies in a radial plane intersecting the longitudinal axis of the fruit, and is auriform to half-elliptic in shape. Wing venation uniformly oriented at $\sim 30-40^{\circ}$ from fruit's central axis. Venation consists of numerous fine veins, frequently dichotomizing, forming loops en route to margin, with secondary veins interconnecting and forming a reticulum with areoles $0.7-1.5 \mathrm{~mm}$. Freely ending veinlets not clear (possibly due to limitations of preservation). Marginal and intramarginal veins absent. One of the five wings bifurcates a third of the distance to the margin, giving that wing a $\mathrm{Y}$-shaped configuration as viewed in cross section.

Specimens examined. USNM 36005 (holotype), 39906, 39907a-c, 39908; UF 1580646363 , 15806-48320, 15806-59166, 158067085, 15806-70851, 15811-59207,15815-43629, 15815-43629', 15815-48321, 15815-48323, 15815-48324', 15815-48325, 15815-48326(1), 15815-48326(2), 15815-48327, 15815-48329', 15820-48318, 15826-48331, 15826-51403, 18810-48386, 18884-32723(1), 18884-32723(2), 18884-32781, 18884-32781', 18884-61106, 18903-045854, 18952-046090, 18952-046090', 18952-46057, 18952-46057', 19326-55599, 19326-55600, 19326-55600', 19326-55601(1), 19326-55601(2), 19326-55602, 19326-55631, 19326-55632.

Localities and number of specimens observed. Specimens were collected from the following commercial clay pits: Bell City, Kentucky (UF 15803; 1 specimen), Buchanan, Tennessee (UF15806; 5 specimens), Como, Tennessee (UF18810; 1 specimen), Dawson, Tennessee (UF18903, 19326; 8 specimens), Grable, Tennessee (UF18952; 2 specimens), Lamkin, Kentucky (UF15815; 7 specimens), Lawrence, Tennessee (UF15816; 2 specimens), Puryear, Tennessee (UF15820; 7 specimens), Warman, Tennessee (UF15826; 2 specimens), Dawson, Tennessee (UF18903; 1 specimen), Wilbank, Tennessee (UF18884; 4 specimens).

Comments. This species is common in clay pits of the middle Eocene Claiborne Formation in Tennessee and Kentucky. Important features of this fossil fruit include apparent indehiscence, a fusiform central body, and the presence of five main wings with fine venation that dichotomizes. The position of the ovary, whether inferior or superior, was initially uncertain because no pedicels or styles are preserved, but the CT scanning of a specimen from the Wilbank locality revealed a pedicel scar, defining the base of the fruit (Pl. 1, figs 16, 17) and indicating that sepals arising from the opposite end are epigynous. Hence we can infer that the fruits developed from an inferior ovary. Although the fossils are flattened through compression, the remnant carbonaceous fragments over the central body of the fruit (e.g., Pl. 1, fig. 2, 12; Pl. 2, figs 1,2 ) indicate that there was more sclerified tissue in the seed-bearing portion than in the wings. In many specimens these carbonaceous remnants have fallen away, revealing a longitudinally striate texture over the central body (Pl. 1, fig. 6).

The holotype of Carpolithus prangosoides (Berry, 1916; refigured here, Pl. 1, fig. 3) does not show the wing venation clearly, but it does display a pair of elongate lateral wings that can be matched with more complete and wellpreserved specimens later described as Terminalia vera Berry $(1926,1930)$. The elongated central bulge in the holotype, representing the fruit body, shows a median longitudinal groove (Pl. 1, fig. 3) which we interpret as the impression of a third wing; the fragmentary counterpart of this specimen shows at least one additional groove into the clay, which we interpret as yet another wing.

Most of the C. prangosoides specimens are exposed in longitudinal fractures of the clay matrix that show only two visible wings, positioned laterally on either side of the fusiform/ 

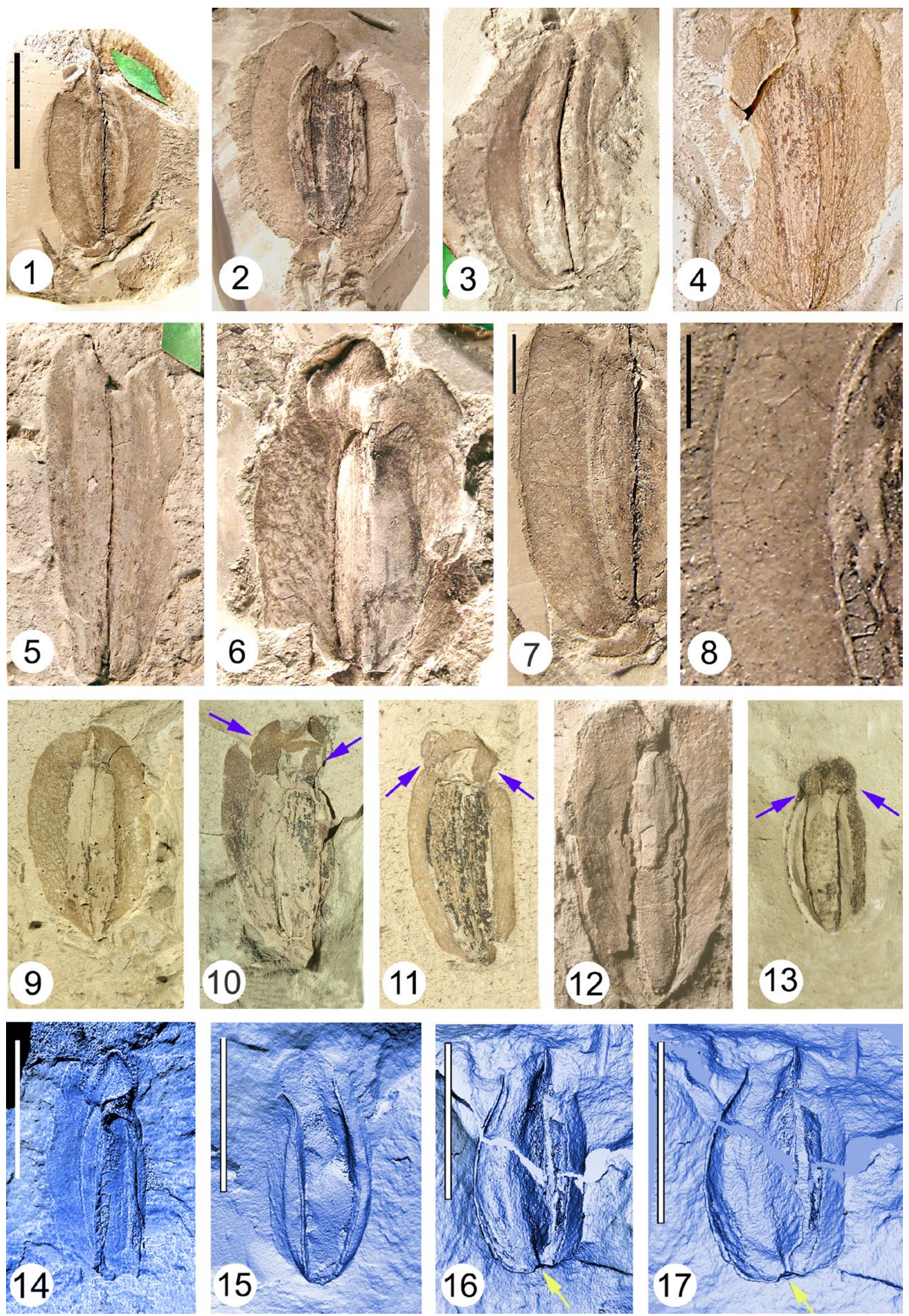
elliptical central body and lying in a common plane (Pl. 1, figs 1, 2, 9). This configuration is an artifact of the horizontal orientation of the fruit within the sediment in which it was buried, and of the lengthwise plane through the sediment that intercepted and exposed the fossil. In describing $T$. vera, Berry $(1926,1930)$ indicated that the fruits possessed only two wings. However, careful microscopy of some specimens shows a stair-step fracture pattern, which reveals multiple levels on which different wings are exposed (Pl. 1, figs 4, 12). In order to determine the full number of wings, two specimens were deliberately fractured transversely in the laboratory, and this showed unequivocally that there were five wings ( $\mathrm{Pl}$. 2, figs 3 , 4). In addition, three specimens were micro-CT-scanned to show the wings in virtual sections and to use those in presenting 3-dimensional reconstructions (Pl. 1, figs 14-17; Pl. 2, figs 8, 9).

Because pedicels have not been found attached to the fruits, it may be inferred either that the fruits were sessile or that they were shed by abscising from the top of the pedicel. The fruits show no indication of a stipe, the presence of which is helpful for identification of some genera of extant fin-winged fruits. The persistent sepals are seen as prominent rounded lobes $2.1-3.5 \mathrm{~mm}$ high and $2.0 \mathrm{~mm}$ wide, arising from the apical end of the fruit body (e.g., Pl. 1, figs 6, 10-16; Pl. 2, figs 5, 12). Micro-CT scan imagery shows that the sepals alternate in position versus the wings (Pl. 1, figs 14-16). None of the specimens show styles, and the number of locules and seeds is still unknown.

In digital transverse sections and surface reconstructions of the specimen examined by micro-CT, one of the wings appeared to have a Y-shaped cleft (Pl. 2, figs 8, 9). This bifurcation of one of the wings was also present in a physically cross-sectioned fruit (Pl. 2, figs 3,4$)$. This cleft may be the product of overlapping wings; however, in Plate 2, figures 8 and 9 , the divided portion of the wing is continuous along the full length of the fruit.

\section{SYSTEMATIC COMPARISONS}

Earlier, this species was assigned to the Combretaceae based on its morphology and lateral wings (Berry 1926, 1930), but a detailed comparison of wing venation distinguishes the fossil from most of the genera within this family. The winged fruits of Combretum and Terminalia have very closely spaced fine veins of a single order without loops or reticulum, and also contain a fusiform central body positioned above the base of the fruit (Manchester and O'Leary, 2010). The fossil, in contrast, has at least four orders of veins. The complex system with primary veins forming loops and subdivided by secondaries and higher-order veins is similar to the venation in the wings of some other combretaceous genera, including Calycopteris, Dansiea and Macropteranthes. However, Calycopteris does not have a fin-winged fruit; rather its wings are arranged like a propeller around the apex and are derived from an accrescent perianth. Macropteranthes and Dansiea are fin-winged, with four wings derived from two folded accrescent prophylls (Stace, 2007). The wing venation in these genera is strikingly similar to that of the fossil; however, the orientation of the main veins is radiating in the modern genera, but mostly apically directed (consistently $\sim 30^{\circ}$ from the axis) in the fossil. In addition, the geometry of

Plate 1. Fruits of Carpolithus prangosoides. 1. Fruit showing two lateral wings, ellipsoidal central body with median longitudinal groove representing an additional wing protruding into the matrix. Grable clay pit, USNM39906; 2. Fruit with residual carbon fragments over central body, indicating thicker portion of fruit, with wings on either side. Bell City, USNM39908; 3. Holotype. Puryear clay pit, USNM36005; 4. Reticulate venation pattern on wings. Puryear clay pit, USNM39907 B; 5. Elongate fruit, with prominent median groove representing a wing facing away from the viewer. Puryear clay pit, USNM39907 C; 6. Apical portion of fruit with apical lobing representing sepals flattened during fossil formation. Puryear clay pit, USNM39907 A; 7. Detail of wing venation from fig. 1; 8. Detail of specimen in fig. 2. Fine veins show looping patterns, carbonaceous remnants of compressed fruit body seen at lower right; 9. Fruit with obvious lateral wings. The strong longitudinal median groove represents another wing directed into the clay. Grable clay pit, UF18952-48509; 10. Specimen with portion of wing well-preserved on left margin, and apical sepal lobes (arrows). Lamkin clay pit, UF15815-43629; 11. Fruit with prominent apical sepal lobes (arrows) and carbon fragmentation over fruit body. Lamkin clay pit, UF15815-48326; 12. Fruit with smooth central body and prominent lateral wings. Puryear clay pit, UF15820-48318; 13. Smaller fruit with a pair of longitudinal grooves representing wings on either side of the central body, and rounded apical lobes representing sepals (arrows). Dawson clay pit, UF18903-45854; 14-17. Depth map images from micro-CT scanning; 14. Fruit with prominent apical lobe (sepal) and longitudinal wings. Wilbank clay pit, UF18884$32781 ; 15$. Same specimen as fig. 13, surface viewed from behind, showing two protruding longitudinal wings, and apical sepals alternating with the wings; 16. Same specimen, tilted slightly, showing basal attachment scar (arrow); this shows that the fruits have inferior ovaries; 17. Same, further tilted, and more enlarged to show basal attachment scar (arrow) and lateral wings; Scale bar: $1 \mathrm{~cm}$ in $1-5,9-17,0.5 \mathrm{~cm}$ in 6,$7 ; 0.25 \mathrm{~cm}$ in 8 ; bar in 1 applies also to 2-5 and 9-13 
the five-winged fruit of $C$. prangosoides would be difficult to reconcile with the four-wing configuration of Dansiea and Macropteranthes, which is derived from paired, folded prophylls.
Carpolithus prangosoides fruits were apparently indehiscent and dispersed individually, because only whole fruits are found, and individually shed wings or mericarps have
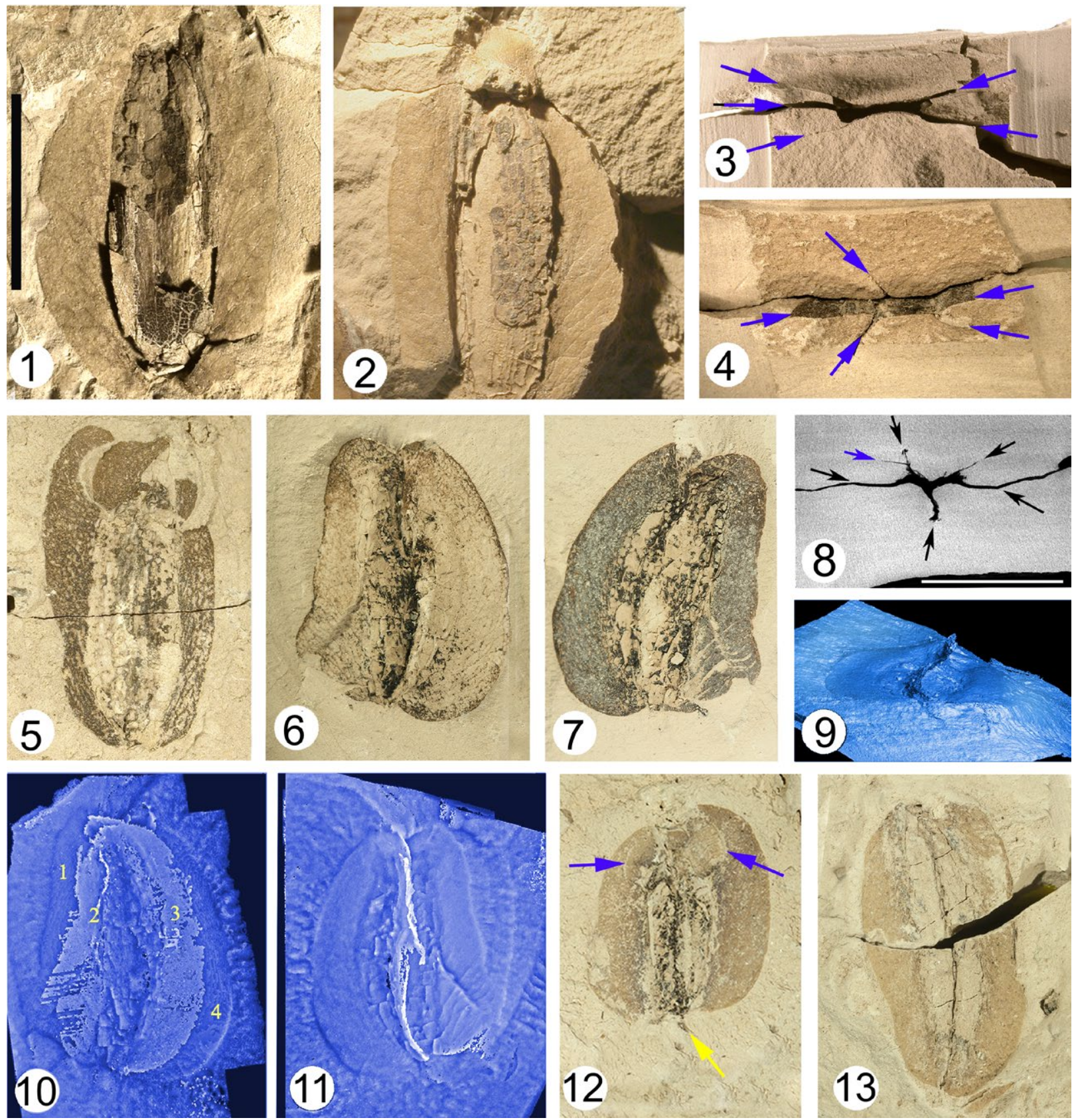

Plate 2. Fruits of Carpolithus prangosoides. 1. Fruit with longitudinally striate ellipsoidal central body with adhering carbon fragments, and a pair of lateral wings with reticulate venation. Wilbank clay pit, UF18884-32723; 2. Counterpart of specimen in fig. 1, showing rounded apical sepal arising above fruit body, Wilbank clay pit, UF18884-32723; 3. Intentional transverse fracture of specimen from figs 1 and 2, showing five radiating wings (arrows). Wilbank clay pit, UF18884-32723; 4. The transverse fracture of specimen from fig. 5, showing five wings radiating from central body (arrows). Wilbank clay pit, UF15815-48329; 5. Fruit with prominent lateral wings and sepal lobes (arrows), UF15815-48329; 6. Opposing counterpart of specimen in fig. 7. Detail of wing fragmentation due to splitting. Warman clay pit, UF19326-55600; 7. Opposing counterpart of specimen in fig. 6. Thicker carbon fragmentation. Warman clay pit, UF19326-55600; 8. Digital transverse section from MicroCT scan of the specimen in figs 6 and 7 (both counterparts reassembled), showing 5 main wings (black arrows) and Y-shaped cleft with additional minor wing (blue arrow); 9. Surface rendering of the same specimen as fig. 6, from micro-CT scan data, viewed obliquely from base, showing three of the wings; 10. Micro-CT depth map image from specimen in fig. 7, showing 4 lateral wings (numbered). Warman clay pit, UF19326-55600; 11. Micro-CT depth map image from specimen in fig. 6, showing additional wing projecting toward viewer, as well as the two wings in plane of compression; 12. One of the smallest and shortest fruits, but with prominent sepal lobes (blue arrow). Yellow arrow marks remnant of an additional wing. Warman clay pit, UF15826-4833; 13. Elliptical fruit with prominent lateral wings and a median groove indicating the position of another wing protruding into the matrix. Lamkin clay pit, UF15815-48327. Scale bars $=1 \mathrm{~cm}$; bar in 1 applies also to $2-7,9-13$ 
not been observed. Therefore these are readily distinguished from the schizocarpic fruits of various angiosperm genera (e.g., Abronia, Bulnesia, Craigia, Dodonaea, Kleinhovia, Sarcozygium, Tribulus, Zygophyllum). Nor have we seen evidence of an apical opening through which seeds might have been shed, as occurs in Dioscorea, Oenothera and other genera.

We compared $C$. prangosoides with the finwinged fruits of 144 extant genera surveyed by Manchester and O'Leary (2010); many of these can be eliminated by the number of wings. Twenty-three of the genera possess five wings, including some in the families Apiaceae, Lophopyxidaceae, Malvaceae and Zygophyllaceae. The fruits of Zygophyllaceae are mericarps, unlike C. prangosoides. Pentace of the Malvaceae has 5-winged fruits with similar venation, but the wing edges in this genus are reinforced by many dichotomies near the margin. Fruits of Apiaceae do not have prominent venation and thus differ from our fossils. Lophopyxidaceae lacks the looping pattern of venation on the fruits, and has significantly higher vein density than the fossil (5 vs 1-2 veins per $\mathrm{mm}$ ).

The absence of an intramarginal vein distinguishes C. prangosoides from Halesia (Styracaceae) and Rheum (Polygonaceae), while the absence of a prominent fimbrial or marginal vein on the wings distinguishes this species from many other taxa such as Tripterocalyx (Nyctaginaceae) and Urvillea (Sapindaceae). Other genera of angiosperms with a similar pattern of venation include Ptelea (Rutaceae), Tripterigium and Wimmeria (Celastraceae), Bulnesia (Zygophyllaceae), Tropaeolum (Tropaeolaceae) and Pterodiscus (Pedaliaceae). However, none of these genera possess the same number of wings as the fossil.

The positioning of the perianth, whether epigynous or hypogynous, is another character important for narrowing down potential affinities of these winged fruits (Manchester and O'Leary, 2010). As observed in the microCT reconstructions, we identified the ovary as inferior because there is an attachment scar at the end opposite to the perianth lobes $(\mathrm{Pl}$. 1, figs 16,17$)$. Of the 144 genera surveyed by Manchester and O'Leary, only six matched in both number of wings and position of the ovary. These include Combretum, Terminalia (Combretaceae), Heteromorpha, Molopospermum, Polemanniopsis, and Prangos (Apiaceae). As described above, both Combretum and Terminalia differ in venation and lack persistent sepals. The fruits of Apiaceae are distinguished by being schizocarpic and they usually have persistent styles.

Despite the additional characters now known for this fossil, the affinities to extant angiosperm taxa remain undetermined. Based on available characters, it conforms to the Eudicot clade. The merosity of wings and sepals is consistent with a position in the Pentapetalae. However, the prior suggestion of combretaceous affinity is rejected based on differences of wing venation. It would be desirable to know more details concerning the pedicel, perianth remnants and styles of this fossil species.

\section{GENERAL DISCUSSION}

Fruits of Combretaceae, Dilcherocarpon combretoides, have been recognized from the early Cretaceous (late Albian) Dakota Formation of Kansas and Nebraska based on small 4-winged disseminules with venation and morphology consistent with modern fruits of the family (Manchester and O'Leary, 2010). However, most of the Cenozoic reports of this family in North America remain questionable. As we have shown, the fruits once treated as Terminalia from the Eocene of Tennessee and Kentucky do not conform to the family.

Another Eocene record, from the Chalk Bluffs flora of California, was called Terminalia estamina MacGinitie (1941) based on leaves and a fragmentary fruit. The leaves were subsequently transferred by that author to Mastixia estamina (MacGinitie) MacGinitie (1969), leaving the fruit specimen in taxonomic limbo. The fruit specimen shows at least four longitudinal wings radiating from an ellipsoidal fruit body, and fine venation that is more widely spaced than is usual for extant Terminalia and Combretum. The taxonomic affinities are in need of reevaluation.

Fossil winged fruits named Terminalia oregona (Lakhanpal) Meyer et Manchester (Lakhanpal, 1958; Brown, 1959; Meyer and Manchester, 1997) are known from a number Oligocene sites in Oregon. The fruits have a fusiform longitudinally ribbed central body and lateral wings with moderately spaced veins, and have a single style and epigynous perianth remains. The assignment to Combretaceae is reasonable, but the species is in 
need of a reexamination that takes advantage of the newly acquired specimens.

Currently, the familial affinities of Carpolithus prangosoides remain uncertain despite the large number of specimens studied and its presence at several different sites. Features still unknown that would be helpful for taxonomic placement include details of the style and stigma, dimensions of the pedicel, and characters of the seeds and their placentation. Overall, the lack of any strong character placing these fruits in this family, and the lack of a critical examination of leaves formerly placed in Combretaceae, mean that we have no confirmation of Combretaceae in the Eocene of North America.

\section{ACKNOWLEDGEMENTS}

We thank Elizabeth O'Leary for help with initial comparative work, Scott Wing and Jonathan Wingerath for access to specimens at USNM, Hongshan Wang for curatorial assistance, Terry Lott for helpful technical assistance, and two anonymous reviewers for their valuable advice.

\section{REFERENCES}

Berry E.W., 1916. The Lower Eocene floras of southeastern North America. U.S. Geological Survey Professional Paper 91, 1-481.

Berry, E.W., 1926. Terminalia in the lower Eocene of southeastern North America. Bulletin of the Torrey Botanical Club 53, 59-65.

Berry, E.W., 1930. Revision of the Lower Eocene Wilcox flora of the southeastern United States. U.S. Geological Survey Professional Paper 156, 1-196.

Brown, R.W., 1959. A bat and some plants from the Upper Oligocene of Oregon. Journal of Paleontology $33,125-129$.

Cignoni, P., Callieri, M., Corsini, M., Dellepiane, M., Ganovelli, F., Ranzuglia, G., 2008. MeshLab: an open-source mesh processing tool. In: Scarano, V., De Chiara, R., Erra, U. (eds), Sixth Eurographics
Italian Chapter Conference. Geneva: Eurographics Association, pp. 129-136.

Dilcher, D.L., Potter, F.W. Jr., 1980. Biostratigraphic analysis of Eocene clay deposits in Henry County, Tennessee. In: Dilcher, D.L., Taylor, T.N. (eds), Biostratigraphy of fossil plants, Dowden, Hutchinson \& Ross, Inc., Stroudsburg, pp. 211-225.

Elsik W.C., Dilcher, D.L., 1974. Palynology and age of clays exposed in Lawrence Clay Pit, Henry County, Tennessee. Palaeontographica Abt. B 146, 65-87.

Lakhanpal, R.N., 1958. The Rujada flora of west central Oregon. University of California Publications in Geological Sciences 35, 1-65.

MacGinitie, H.D., 1941. Middle Eocene flora from the central Sierra Nevada. Carnegie Institution of Washington Publication 534, pp. 1-178.

MacGinitie, H.D., 1969. The Eocene Green River flora of northwestern Colorado and northeastern Utah. University of California Publications in Geological Sciences 83, 1-140.

Manchester, S.R., O’Leary, E.L., 2010. Phylogenetic distribution and identification of fin-winged fruits. Botanical Review 76, 1-82.

Meyer, H.W., Manchester, S.R., 1997. The Oligocene Bridge Creek flora of the John Day Formation, Oregon. University of California Publications in Geological Sciences 141, 1-195, 75 pl.

Mirle, C., Burnham, R., 1999. Identification of asymmetrically winged samaras from the Western Hemisphere. Brittonia 51, 1-14.

Moore, B.R., Dilcher, D.L., Gibson, M.A., 2003. Paleoenvironment, depositional setting, and plant fossil diversity found in the Claiborne Formation (middle Eocene) clay deposits of western Tennessee. In: Cox, R.T. (ed.), Field Trip Guidebook, Joint Meeting South-Central and Southeastern Sections of Geological Society of America. State of Tennessee, Department of Environment and Conservation, Division of Geology, Report of Investigations, 51, 187-198.

Stace, C.A., 2007. Combretaceae. In: Kubitzki, K. (ed.), The families and genera of vascular plants. Vol. IX Flowering Plants. Springer, Berlin, pp. 67-81.

Wang, H., Blanchard, J., Dilcher, D.L., 2013. Fruits, seeds, and flowers from the Warman clay pit (middle Eocene Claiborne Group), western Tennessee, USA. Palaeontologia Electronica 16(3), 1-73. 